\title{
Prognostic Significance of High Androgen Receptor Expression in Prostatic Acinar Adenocarcinoma
}

\author{
Atif Ali Hashmi ${ }^{1 *}$,Ghazala Mudassir ${ }^{2}$,Muhammad Irfan ${ }^{3}$, Zubaida Fida \\ Hussain ${ }^{1}$, Shumaila Kanwal Hashmi ${ }^{4}$, Huda Asif ${ }^{5}$, Laila Nisar ${ }^{6}$, Maheen Naeem ${ }^{6}$, \\ Naveen Faridi ${ }^{1}$
}

\begin{abstract}
Background: Quantitative immunohistochemical expression of Androgen receptor (AR) has not been evaluated as a prognostic biomarker of prostate cancer in our population, therefore in the current study we aimed to evaluate the association of AR expression in prostatic acinar adenocarcinoma with various prognostic parameters like tumor quantification, Gleason score, WHO grade group and perineural invasion. Methods: Total 121 cases of biopsy proven prostatic acinar adenocarcinoma were selected from records of pathology department archives from January 2013 till December 2017. Hematoxylin and eosin stained slides and paraffin blocks were retrieved and new sections were cut where necessary. Slides of all cases were reviewed by two senior histopathologists and pathologic characteristics like Gleason score, WHO grade, tumor quantification, perineural and lymphovascular invasion were evaluated. Androgen receptor immunohistochemistry was applied on all cases. Results: Low AR expression was noted in 53 cases (43.8\%) while high AR expression was seen in 68 cases (56.2\%). Significant association of AR expression was noted with total Gleason score, WHO grade and percentage of tissue involvement (tumor quantification). Univariate binary logistic regression showed patients with low Gleason scores (scores 6,7 or 8) and low WHO grade (grade 1, 2 or 3) were less likely to express high AR expression in comparison to high Gleason score (score 9) and high WHO grade group (grade 5) respectively. Similarly, cases with low tissue involvement by carcinoma $(<50 \%)$ were less likely to show high AR expression in comparison to cases with $>50 \%$ tissue involvement by carcinoma. Conclusion: Significant association of AR expression was noted with total Gleason score, WHO grade and percentage of tissue involvement (tumor quantification) which are among the most important markers of tumor progression; therefore we suggest that AR expression should be performed in patients with prostatic adenocarcinoma for prognostic stratification of the patients.
\end{abstract}

Keywords: Androgen receptor- AR- prostatic carcinoma- Gleason score- WHO grade group

Asian Pac J Cancer Prev, 20 (3), 893-896

\section{Introduction}

Androgens (testosterone and dihydrotestosterone) act through androgen receptor (AR) and this interaction is required for normal prostate development (Roy et al., 1999; Cunha et al., 1987). It is believed that prostatic carcinogenesis is androgen mediated, however serum androgens can't promote carcinogenesis alone, hence functional status of androgen receptor (AR) is the most important mediator of prostate cancer progression. Low serum testosterone in prostate cancer patients was found to be associated with high AR expression which in turn is linked to higher Gleason score (Schatzl et al., 2002). Recent studies also revealed that high AR expression was correlated with disease progression and lower recurrence free survival (Lee, 2003). Quantitative immunohistochemical (IHC) expression of AR has not been evaluated as a prognostic biomarker of prostate cancer in our population, therefore in the current study we aimed to evaluate the association of AR expression with various prognostic parameters like tumor quantification, gleason score, WHO grade group and perineural invasion.

\section{Materials and Methods}

Case Selection: Total 121 cases of biopsy proven prostatic acinar adenocarcinoma were selected from records of pathology department archives. All patients underwent surgeries at Liaquat National hospital, Karachi from January 2013 till December 2017 over a period of 5 years. The study was approved by research and ethical review committee of Liaquat National Hospital and

${ }^{1}$ Department of Histopathology, ${ }^{3}$ Department of Statistics, Liaquat National Hospital and Medical College, ${ }^{6}$ Liaquat National School of Diagnostic Laboratory Sciences, Karachi, ${ }^{2}$ Department of Pathology, Shifa College of Medicine, Islamabad, ${ }^{4}$ Department of Pathology, CMH Institute of Medical Sciences, ${ }^{5} \mathrm{CMH}$ Institute of Medical Sciences, Multan, Pakistan. *For Correspondence:doc_atif2005@yahoo.com 
informed written consent was taken from all patients at the time of surgery. Hematoxylin and eosin stained slides and paraffin blocks were retrieved and new sections were cut where necessary. Slides of all cases were reviewed by two senior histopathologists and pathologic characteristics like Gleason score, WHO grade, tumor quantification, perineural and lymphovascular invasion were evaluated. Specimens included prostatic chips and radical prostatectomies. Moreover, representative tissue blocks of all 121 cases were selected for AR immunohistochemistry (IHC).

Androgen Receptor (AR) Immunohistochemistry: AR IHC was performed using DAKO EnVision method using monoclonal mouse anti-human androgen receptor; clone AR441 according to manufacturer's protocol (dilution of 1:50). Nuclear staining for AR was both quantitatively and qualitatively evaluated. Intensity of staining was scored into no staining $(0)$, weak $(1+)$, intermediate $(2+)$, strong $(3+)$ while percentage of positively stained cells were scored as continuous variable (figure 1). Intensity and percentage scores were multiplied to generate an H-score ranging from 0-300. A cut-off value of 200 was used to categorize AR expression into low and high.

Statistical Analysis: Statistical package for social sciences (SPSS 21) was used for analysis. Mean and standard deviation were calculated for quantitative variables. Frequency and percentage were evaluated for qualitative variables. Normality was checked by Shapiro wilk test. Mean comparison was done by using mann whitney $\mathrm{U}$ test and Kruskal wallis $\mathrm{H}$ test as appropriate. Chi square test was applied to determine association. Odds were calculated for significant variables by univariate binary logistic regression. P-value $\leq 0.05$ was taken as significant.

\section{Results}

Patients Characteristics: Mean age of the patients was $67.81+10.12$ years. $22.3 \%$ (27 cases) and 30.6\% (37
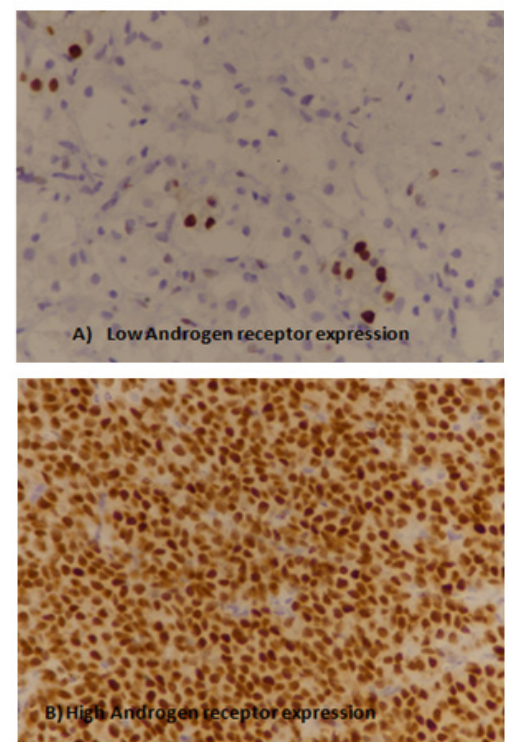

Figure 1. Androgen Receptor (AR) Expression in Prostatic Acinar Adenocarcinoma, A) Low AR expression, 100X magnification, B) High AR expression, 100X magnification cases) were of Gleason score 8 and 9 respectively. There was no case of Gleason score 10 or below 6. Similarly, $30.6 \%$ (37 cases) were having WHO grade group 5. 52.1\% (63 cases) revealed $>50 \%$ tissue involvement by prostatic carcinoma. Perineural invasion was noted in 37.2\% (45 cases) as shown in Table 1.

Androgen receptor expression: Low AR expression was noted in 53 cases $(43.8 \%$ ) while high AR expression was seen in 68 cases $(56.2 \%)$. Significant association

Table 1. Clinicopathologic Characteristics of Studied Population $(\mathrm{n}=121)$

\begin{tabular}{|c|c|}
\hline & $\mathrm{n}(\%)$ \\
\hline \multicolumn{2}{|l|}{ Age (years) } \\
\hline Mean \pm SD & $67.81 \pm 10.12$ \\
\hline \multicolumn{2}{|l|}{ Groups } \\
\hline$<40$ years & $2(1.7)$ \\
\hline $40-70$ years & $75(62)$ \\
\hline$>70$ years & $44(36.4)$ \\
\hline \multicolumn{2}{|c|}{ Tumor Quantification (\%) } \\
\hline Mean \pm SD & $47.59 \pm 32.16$ \\
\hline \multicolumn{2}{|l|}{ Groups } \\
\hline$<10 \%$ & $29(24)$ \\
\hline $10-50 \%$ & $29(24)$ \\
\hline$>50 \%$ & $63(52.1)$ \\
\hline \multicolumn{2}{|l|}{ Total gleason score } \\
\hline 6 & $22(18.2)$ \\
\hline 7 & $35(28.9)$ \\
\hline 8 & $27(22.3)$ \\
\hline 9 & $37(30.6)$ \\
\hline \multicolumn{2}{|l|}{ WHO grade group } \\
\hline Grade 1 & $22(18.2)$ \\
\hline Grade 2 & $17(14)$ \\
\hline Grade 3 & $18(14.9)$ \\
\hline Grade 4 & $27(22.3)$ \\
\hline Grade 5 & $37(30.6)$ \\
\hline \multicolumn{2}{|l|}{ Perineural invasion } \\
\hline Present & $45(37.2)$ \\
\hline Absent & $76(62.8)$ \\
\hline \multicolumn{2}{|c|}{ Lymphovascular invasion } \\
\hline Present & $3(2.5)$ \\
\hline Absent & $118(97.5)$ \\
\hline \multicolumn{2}{|c|}{ Extraprostatic extension } \\
\hline Present & $8(6.6)$ \\
\hline Absent & $113(93.4)$ \\
\hline \multicolumn{2}{|c|}{ Seminal vesicle invasion } \\
\hline Present & $6(5)$ \\
\hline Absent & $115(95)$ \\
\hline \multicolumn{2}{|l|}{ Androgen Score } \\
\hline Mean \pm SD & $71.52 \pm 21.84$ \\
\hline \multicolumn{2}{|l|}{ Groups } \\
\hline Low Expression & $53(43.8)$ \\
\hline High Expression & $68(56.2)$ \\
\hline
\end{tabular}


Table 2. Association Androgen Receptor Expression with Clinicopathologic Parameters in Prostatic Acinar Adenocarcinoma

\begin{tabular}{ccc}
\hline \multicolumn{2}{c}{$\mathrm{n}(\%)$} & P-Value \\
Low & High & \\
Expression & Expression & \\
$(\mathrm{n}=53)$ & $(\mathrm{n}=68)$ & \\
\hline
\end{tabular}

\begin{tabular}{|c|c|c|c|}
\hline \multicolumn{4}{|l|}{ Age Group $\underline{\imath}$} \\
\hline$<40$ years & $0(0)$ & $2(2.9)$ & 0.536 \\
\hline $40-70$ years & $32(60.4)$ & $43(63.2)$ & \\
\hline$>70$ years & $21(39.6)$ & $23(33.8)$ & \\
\hline \multicolumn{4}{|c|}{ Total gleason score } \\
\hline 6 & $18(34)$ & $4(5.9)$ & 0 \\
\hline 7 & $22(41.5)$ & $13(19.1)$ & \\
\hline 8 & $7(13.2)$ & $20(29.4)$ & \\
\hline 9 & $6(11.3)$ & $31(45.6)$ & \\
\hline \multicolumn{4}{|c|}{ WHO grade group } \\
\hline Grade 1 & $18(34)$ & $4(5.9)$ & 0 \\
\hline Grade 2 & $12(22.6)$ & $5(7.4)$ & \\
\hline Grade 3 & $10(18.9)$ & $8(11.8)$ & \\
\hline Grade 4 & $7(13.2)$ & $20(29.4)$ & \\
\hline Grade 5 & $6(11.3)$ & $31(45.6)$ & \\
\hline \multicolumn{4}{|c|}{ Tumor Quantification } \\
\hline$<10$ & $21(39.6)$ & $8(11.8)$ & 0 \\
\hline $10-50$ & $17(32.1)$ & $12(17.6)$ & \\
\hline$>50$ & $15(28.3)$ & $48(70.6)$ & \\
\hline \multicolumn{4}{|c|}{ Perineural invasion } \\
\hline Present & $22(41.5)$ & $23(33.8)$ & 0.385 \\
\hline Absent & $31(58.5)$ & $45(66.2)$ & \\
\hline \multicolumn{4}{|c|}{ Lymphovascular invasion $\_$} \\
\hline Present & $2(3.8)$ & $1(1.5)$ & 0.581 \\
\hline Absent & $51(96.2)$ & $67(98.5)$ & \\
\hline \multicolumn{4}{|c|}{ Extraprostatic extension $\_$} \\
\hline Present & $6(11.3)$ & $2(2.9)$ & 0.136 \\
\hline Absent & $47(88.7)$ & $66(97.1)$ & \\
\hline \multicolumn{4}{|c|}{ Seminal vesicle invasion $\_$} \\
\hline Present & $5(9.4)$ & $1(1.5)$ & 0.085 \\
\hline Absent & $48(90.6)$ & $67(98.5)$ & \\
\hline
\end{tabular}

Chi square test applied; $\underline{\uparrow}$ Fisher exact test applied; P-Value $\leq 0.05$; considered as significant.

of AR expression was noted with total Gleason score, WHO grade and percentage of tissue involvement (tumor quantification). Statistically insignificant association of AR expression was noted with other variables including perineural invasion, lymphovascular invasion, extra-prostatic extension and seminal vesicle invasion (Table 2). Perineural invasion was noted in $33.8 \%$ of tumors showing high AR expression. Similarly, lymphovascular invasion, extra-prostatic extension and seminal vesicle invasion was seen in $1.5 \%, 2.9 \%$ and $1.5 \%$ of cases respectively, however, the association with AR expression was not significant ( $\mathrm{p}=>0.05$ ).

Univariate binary logistic regression showed that patients with low Gleason scores (scores 6,7 or 8 ) and low
Table 3. Odds Ratio for Patients with High Androgen Expression

\begin{tabular}{lcc}
\hline & odds ratio $(95 \% \mathrm{CI})$ & P-Value \\
\hline Total gleason score & & \\
6 & $0.043(0.011-0.173)$ & 0 \\
7 & $0.114(0.038-0.347)$ & 0 \\
8 & $0.553(0.162-1.886)$ & 0.344 \\
$9^{\circledR}$ & 1 & \\
WHO grade group & & \\
Grade-I & $0.043(0.011-0.173)$ & 0 \\
Grade-II & $0.081(0.021-0.315)$ & 0 \\
Grade-III & $0.155(0.043-0.555)$ & 0.004 \\
Grade-IV & $0.553(0.162-1.886)$ & 0.344 \\
Grade-V & 1 & \\
Tumor Quantification & $0.119(0.044-0.323)$ & 0 \\
$<10$ & $0.221(0.086-0.564)$ & 0.002 \\
$10-50$ & 1 & \\
$>50^{\circledR}$ & & \\
\hline Univariate binary logistic & regression was applied; P-Value $\leq 0.05$, \\
considered as significant. &
\end{tabular}

Table 4. Comparison of Mean Androgen Receptor Expression (H-Score) with Clinicopathologic Parameters

\begin{tabular}{|c|c|c|}
\hline & Mean \pm SD & P-Value \\
\hline \multicolumn{3}{|l|}{ Age Group ${ }^{\mathrm{TM}}$} \\
\hline$<40$ years & $90.00 \pm 0.000$ & 0.188 \\
\hline $40-70$ years & $70.26 \pm 24.18$ & \\
\hline$>70$ years & $72.84 \pm 17.43$ & \\
\hline \multicolumn{3}{|c|}{ Total gleason score ${ }^{\mathrm{TM}}$} \\
\hline 6 & $57.27 \pm 26.75$ & 0 \\
\hline 7 & $62.85 \pm 23.14$ & \\
\hline 8 & $75.37 \pm 14.73$ & \\
\hline 9 & $85.40 \pm 10.16$ & \\
\hline \multicolumn{3}{|l|}{ WHO grade ${ }^{\mathrm{TM}}$} \\
\hline Grade 1 & $57.27 \pm 26.75$ & 0 \\
\hline Grade 2 & $66.47 \pm 18.68$ & \\
\hline Grade 3 & $59.44 \pm 26.78$ & \\
\hline Grade 4 & $75.37 \pm 14.73$ & \\
\hline Grade 5 & $85.40 \pm 10.16$ & \\
\hline \multicolumn{3}{|c|}{ Tumor Quantification ${ }^{\mathrm{TM}}$} \\
\hline$<10$ & $65.17 \pm 18.77$ & 0.001 \\
\hline $10-50$ & $62.58 \pm 29.89$ & \\
\hline$>50$ & $78.57 \pm 15.92$ & \\
\hline \multicolumn{3}{|c|}{ Perineural invasion } \\
\hline Present & $71.33 \pm 21.56$ & 0.644 \\
\hline Absent & $71.64 \pm 22.14$ & \\
\hline \multicolumn{3}{|c|}{ Lymphovascular invasion } \\
\hline Present & $76.66 \pm 2.88$ & 0.652 \\
\hline Absent & $71.39 \pm 22.10$ & \\
\hline \multicolumn{3}{|c|}{ Extraprostatic extension } \\
\hline Present & $55.62 \pm 32.34$ & 0.054 \\
\hline Absent & $72.65 \pm 20.64$ & \\
\hline \multicolumn{3}{|c|}{ Seminal vasicle invasion ${ }^{\mathrm{a}}$} \\
\hline Present & $74.16 \pm 3.76$ & 0.237 \\
\hline Absent & $71.39 \pm 22.38$ & \\
\hline
\end{tabular}

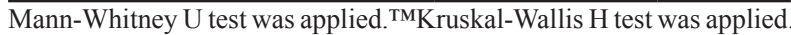
$\mathrm{P}$-Value $\leq 0.05$, considered as significant.

Asian Pacific Journal of Cancer Prevention, Vol 20 
WHO grade (grade 1, 2 or 3) were less likely to express high AR expression in comparison to high Gleason score (score 9) and high WHO grade group (grade 5) respectively. Similarly, cases with low tissue involvement by carcinoma $(<50 \%)$ were less likely to show high AR expression in comparison to cases with $>50 \%$ tissue involvement by carcinoma as shown in table 3 .

Table 4 shows comparison of mean $\mathrm{H}$-score of AR expression with various clinicopathologic parameters revealing significant association of mean high AR expression with higher tumor grade and high tissue involvement by carcinoma.

\section{Discussion}

In the present study we evaluated AR expression in prostatic acinar adenocarcinoma and found high AR expression in $56.2 \%$ of cases. Moreover, high AR expression was associated with high tissue involvement by tumor and higher tumor grade and Gleason score which are among the most important markers of disease progression in prostatic tumors. To our knowledge, this is among the first study in Pakistan evaluating the prognostic significance of AR expression in prostatic carcinoma.

$\mathrm{AR}$ acts an important biomarker in many human cancers especially of genital tract (Hashmi et al., 2018). Prognostic significance of high AR expression has been studied previously. Some authors observed that high AR expression correlates with better tumor differentiation (i.e low Gleason score) (Chodak et al., 1992; Lee et al., 2003; Takeda et al., 1996) while other researchers found a contradictory observation (Hobisch et al., 1996; de Winter et al., 1994). Loss of AR expression in some tumor cells (low AR expression) can be due to many reasons like X-chromosome losses (Alers et al., 2000; Nupponen et al., 1998) or epigenic gene silencing (Sasaki et al., 2002). We found low AR expression in 44\% of cases.

Major limitation of our study was limited number of cases and lack of patients follow up. However, we found that high AR expression is associated with higher percentage of tissue involvement by tumor and higher tumor grade which has important clinical significance.

Significant association of AR expression was noted with total Gleason score, WHO grade and percentage of tissue involvement (tumor quantification) which are among the most important markers of tumor progression; therefore we suggest that AR expression showed be performed in patients with prostatic adenocarcinoma for prognostic stratification of the patients.

\section{Statement conflict of Interest}

All authors declare that there is no conflict of interest.

\section{References}

Alers JC, Rochat J, Krijtenburg PJ, et al (2000). Identification of genetic markers for prostatic cancer progression. $L a b$ Invest, 80, 931.

Cunha GR, Donjacour AA, Cooke PS, et al (1987). The endocrinology and developmental biology of the prostate. Endocr Rev, 8, 338-62.
Chodak GW, Kranc DM, Puy LA, et al (1992). Nuclear localization of androgen receptor in heterogeneous samples of normal, hyperplastic and neoplastic human prostate. J Urol, 147, 798-803.

De Winter JR, Janssen PJ, Sleddens HM, et al (1994). Androgen receptor status in localized and locally progressive hormone refractory human prostate cancer. Am J Pathol, 144, 735.

Hashmi AA, Hussain ZF, Qadri A, et al (2018). Androgen receptor expression in endometrial carcinoma and its correlation with clinicopathologic features. BMC Res Notes, 11, 289.

Hobisch A, Culig Z, Radmayr C, et al (1996). A. Androgen receptor status of lymph node metastases from prostate cancer. Prostate, 28, 129-35.

Lee D, Oh W, Sartor O (2003). High androgen receptor levels are predictive of decreased survival in prostate cancer. Clin Prostate Cancer, 2, 13-4.

Lee DK, Chang C (2003). Expression and degradation of androgen receptor: mechanism and clinical implication. $J$ Clin Endocrinol Metabol, 88, 4043-54.

Nupponen NN, Kakkola L, Koivisto P, Visakorpi T (1998). Genetic alterations in hormone-refractory recurrent prostate carcinomas. Am J pathol, 153, 141-8.

Roy AK, Lavrovsky Y, Song CS, et al (1998). Regulation of androgen action. Vitam Horm, 55, 309-352.

Sasaki M, Tanaka Y, Perinchery G, et al (2002). Methylation and inactivation of estrogen, progesterone, and androgen receptors in prostate cancer. $J$ Nat Cancer Inst, 94, 384-90.

Schatzl G, Madersbacher S, Gsur A, et al (2002).Association of polymorphisms within androgen receptor, $5 \alpha$-reductase, and PSA genes with prostate volume, clinical parameters, and endocrine status in elderly men. Prostate, 52, 130-8.

Takeda H, Akakura K, Masai M, et al (1996). Androgen receptor content of prostate carcinoma cells estimated by immunohistochemistry is related to prognosis of patients with stage D2 prostate carcinoma. Cancer: Interdisciplinary. Int J Am Cancer Soc, 77, 934-40.

\section{@(ब)}

This work is licensed under a Creative Commons AttributionNon Commercial 4.0 International License. 